\title{
EXPERIENCE Demographic Factors \\ AND THEIR INFLUENCE ON INSTRUCTOR \\ Perspectives of Online versus Face-to- \\ Face Education at a Jesuit Institution
}

Lynn A. Fish and Coral R. Snodgrass

Lynn A Fish and Coral R. Snodgrass each hold the rank of Professor of Management, Canisius College, 2001 Main Street, Buffalo, NY 14208

\begin{abstract}
While instructors are a critical component of the education paradigm, research into instructor perspectives on online education are sparse. The purpose of this phase of a larger study is to explore how experience demographic factors affect instructor perceptions at a Jesuit, Catholic private University in the northeast. Previous research from the larger study demonstrated that online and face-to-face instructor perspectives significantly differed on most individual and program factors. The specific demographic factors analyzed in this paper include (a) level taught, (b) number of years teaching, (c) whether the instructor had experienced an online course, and (d) self-reported technological skill level.
\end{abstract}


Keywords: instructor perceptions, online education, instructor experiences

DOI: http://dx.doi.org/10.15239/j.brcacadjb.2019.09.01.ja05

\section{CONTEXT OF THIS STUDY}

The purpose of the study reported in this paper is to further explore differences in instructor perceptions of online (OL) verses face-to-face (FTF) instruction. It is part of a large study examining student and instructor perceptions on various factors related to OL and FTF education. Previously published research from this larger study demonstrates that instructor's perceptions between OL and FTF education significantly differ on most individual and program factors (Fish \& Snodgrass, 2018 a, b, c). Individual factors studied included: motivation, difficulty, discipline, self-directed learning, independence, time and cost investment, happiness, appropriateness of online education for the University. Program factors, which relate to the design of the courses and the activities included in the program design, included: academic integrity, academic program rigor, academic program preference, program quality, communication mechanisms and course activities, course organization, interaction with other instructors, student-to-instructor interaction, student-to-student interaction, and technical program activities.

Theoretically, if the environments are equitable, OL and FTF instructors should be indifferent to the two environments; however, our original research demonstrated significant differences between OL and FTF instructor perceptions for many factors. Instructor perceptions where the instructor did not favor their respective group and the result was significant occurred for several factors. These factors included: motivation, student-to-student interaction, student-to-instructor interaction, cheating, self-directed, time investment, cost investment, preference for the opposite environment, and happiness with the environment (Fish \& Snodgrass, 2018a, b, c). With respect to motivation, the majority of OL 
instructors were indifferent to the two environments, but FTF instructors perceived FTF to be more motivating than OL. Both OL and FTF instructors significantly favored FTF education for student-to-student and student-to-instructor interaction. OL and FTF instructors indicated that it was more difficult to cheat in the FTF classroom than online. FTF instructors perceived FTF as offering a more self-directed environment, while OL instructors varied in their perceptions of self-directedness and many were indifferent. OL instructors perceived online education as requiring more time investment, while on average, FTF instructors were indifferent to the time investment. With respect to cost investment, half of the instructors were indifferent. However, while the other half of the OL instructors were split between the two environments, FTF instructors perceived FTF as requiring more cost investment. The majority of FTF instructors did not wish to teach online, while less than half of the OL instructors preferred to teach FTF. FTF instructors were overwhelmingly happy with teaching in the FTF environment, while $29.3 \%$ of the OL instructors were indifferent to the environments. However, $48.8 \%$ of OL instructors were happier or very happy with teaching online. Instructor perceptions were slightly significant for appropriateness of online (Fish \& Snodgrass, 2018a, b, c). $73.1 \%$ of OL instructors indicated that online was appropriate for the institution, but only $48.8 \%$ of FTF instructors felt online was appropriate. $25.6 \%$ of FTF instructors were undecided as to whether online was appropriate for the institution or not. For the factors of difficulty, discipline, independence, and schedule flexibility, instructors' perceptions were in agreement (Fish \& Snodgrass, 2018a, b, c). With respect to difficulty, discipline, and independence, OL and FTF instructors were relatively indifferent or slightly favored their respective environment. OL and FTF instructors tended to favor online as offering more schedule flexibility.

Since this paper is part of a larger study, the specific intent here is to address the potential differences that the experience factors that an instructor brings to the classroom have on the perceptual differences between instructors who teach online and those that do not. In a 
recent paper, we reported on the instructor demographic factors that an instructor 'brings to the discussion by virtue of who he or she is' (Fish \& Snodgrass, 2018a). In this paper, we address the 'experience factors' that is the 'factors that an instructor acquires by teaching'. Experience factors explored in this portion of the research include: the level the instructor teaches at, the number of years taught at the University and in total, whether the instructor took an online course, and the instructor's selfreported technology level. We continue with a discussion of the limited research on these instructor experiential factors.

\section{LITERATURE REVIEW}

While this is not the first study to examine OL and FTF education, it is clear from a review of the literature that the impact of online education will continue to grow in higher education. Recent research highlighted the increase in online education throughout the higher education system (Allen \& Seamen, 2013). In addition, the issues are ever changing. A recent study on instructor attitudes with respect to instructor online presence noted that studies into instructor and student perceptions continues to evolve as technology evolves (Richardson et al., 2016). In studies of student perceptions of online versus FTF education, gender, age, experience, and academic background yielded differing results over time (Billings, Skiba \& Connors, 2005; Dobbs et al. 2009; Tanner et al., 2004a, 2004b; Fish \& Snodgrass, 2014). There is a need to assess both the student and instructor's perspectives with respect to online education (Shieh, Gummer \& Niess, 2008). Information and knowledge regarding instructor beliefs are important to improving instructional effectiveness (Farrell \& Kun, 2009). The general question before us is 'How do instructors - those that have taught and those that have not taught online - perceive online education compared to FTF education today?' The purpose of this paper is to explore instructor perceptions and associated experiential factors at one Jesuit, Catholic, private institution. 
Research on instructor perspectives demonstrates changing perspectives overtime and differences on many factors. In 2004, faculty perceptions (at public and nonprofit private institutions in the United States) on the effectiveness of online instruction in terms of the seven principles of effective undergraduate education revealed that faculty rated online education slightly more effective overall and more effective for promoting prompt feedback, time on task, respect for diverse learning styles and communicating high expectations (Guidera, 2004). However, online education was rated less effective on promoting student-to-instructor contact and cooperation among students (Guidera, 2004). In 2017, our study found that instructors still favored student-to-instructor interaction in the FTF classroom (Fish \& Snodgrass, 2018a, b, c), Over a decade ago, using the Delphi method, 36 business instructors from AACSB accredited universities who taught online were questioned on best practices in online education (Gallegos Butters, 2007). The study highlighted the need for incentives to professors to teach online and need for professors to learn pedagogy respective to the online environment (Gallegos Butters, 2007). Similarly, in a 2009 survey of over 10,000 faculty members from close to 70 colleges and universities, most instructors felt that their institutions did not provide online support and incentives to teach online (Seaman, 2009). In a 2009 study, instructor perceptions of teaching and learning outcomes were strongly influenced by instructor experience in teaching online as those with positive experiences indicated that online and FTF outcomes were equivalent, while those who never taught online or had negative online experiences, did not feel that online and FTF outcomes were the same (Fish \& Gill, 2009).

However, these surveys were conducted over 8 years ago as MOOCs and online education were just starting to explode. In a literature search on instructor perspectives on online education, there were few studies to address differences in age, gender, experience, major or discipline, level taught, faculty rank and self-reported technological skill level. Of these, age and gender were the most frequently studied. 
With respect to experience, instructors with more experience are growing more comfortable with online teaching (Terosky \& Heasley, 2015). Instructors' perceive online effectiveness was higher for more experienced faculty (Seok et al., 2010), which also increased with the number of online courses taught (Guidera, 2004). Instructors with more than 4 years of experience in teaching online were more attentive to instructional design than facilitating learning and had more facilitating experiences with students (Chang et al., 2014). Another study noted that instructors with more years of teaching experience had a more positive perception of the effectiveness of online professional development and tend to prefer online professional development to FTF professional development (Thomas, 2010). Additionally, online instructors who participated in more online courses responded more positively that their teaching methodology changed due to the online professional development courses (Thomas, 2010). With rapid advances in technology, increasing use of course management systems, instructor comfort levels and increased online teaching experiences contribute to positive perceptions of online course effectiveness (Seok et al., 2010).

There is some limited work done on other demographic factors. With respect to instructor beliefs regarding students, instructors with positive online experiences felt that online teaching catered more to self-motivated and disciplined students as less motivated and those with learning styles favoring traditional teaching were likely to struggle in the online environment (Fish \& Gill, 2009). Significant differences across instructor's technology skills and their perceptions of online effectiveness exist (Seok et al., 2010).

As for the appropriateness of online education, a recent study revealed that some online instructors still question the fit between their educational philosophies and online teaching (Terosky \& Heasley, 2015). In an attempt to address this gap, administrators often point to instructor online orientation and development programs. Research into online faculty development programs cite the need to include the faculty member's needs 
in content and format recommendations as well as the need for 'followup' education and structures that build trust and connections amongst online faculty (Terosky \& Heasley, 2015). Another study highlights the critical importance of the institution's commitment and support to online training prior to the instructor teaching online (Shieh et al., 2008). Early studies reported that not all instructors teaching styles are suited to online teaching (Christianson, Tiene \& Luft, 2002). Another study highlighted the importance of sufficient training and support for faculty to enhance their ability to deliver online instruction (Bennett \& Lockyer, 2004). While instructors' perceptions did not differ significantly between those instructors with or without training support, online instructors who receive enough training support performed better on instructional design, learning assessment, and technology use than online instructors who received little or no training support (Chang et al., 2014). As a faculty member transitions from the traditional FTF to the online environment, faculty perceptions reflect the need for comprehensive training (Chang et al., 2014). The ability to work anytime and from any Internet accessible computer were cited by instructors as factors that influenced their preference to take online professional development courses instead of FTF (Thomas, 2010).

While not intended to be a comprehensive review of literature on instructor perceptions of online education, the literature review serves to outline the lack of research in this area. As noted above, most available research is over a decade old, when available technology and instructor understanding of online education was very different. The few studies performed differ in size (small, medium, large universities), audience (e.g. scientific versus social sciences, business versus non-business, and graduate versus undergraduate), and method of research (e.g. interview, survey). The context of the study may be an important factor to consider in interpretation of the survey results. As we noted in a similar study with respect to student perceptions (Fish \& Snodgrass, 2016a, 2016b) and the studies to address instructor perceptions (Fish \& Snodgrass, 2018 a, b \& c), as technology changes, online education changes and perceptions change 
as well. As noted above, there are very few studies on the experience demographic instructor factors, and many studies that exist are over 10 years old. Therefore, in this paper we specifically explore the relationship between instructor perceptions of online versus FTF and the following factors: (a) the level an instructor teaches at (undergraduate, graduate or both), (b) the number of years that an instructor has taught, (c) whether the instructor has online experience as a student, and (d) the instructor's self-reported technological level. Administrators believe that online and FTF instruction is the same (Allen and Seamen, 2013). If this is the case, then instructors would be indifferent to the educational environment regardless of their own experiences on these factors. With this in mind, specific hypotheses tested are as follows:

\section{Level Taught: Undergraduate, Graduate or Both.}

If instructors are indifferent to OL and FTF, then regardless of whether an instructor teaches undergraduates, graduates or both levels, instructors would be indifferent to OL and FTF. However, if instructors are not indifferent, then their perspectives differ. Specifically:

$\mathrm{H}_{10 \mathrm{~A}}$ : Regardless of the level at which an $\mathrm{OL}$ instructor teaches (undergraduate, graduate or both), OL instructor's perceptions are indifferent between OL versus FTF education.

$\mathrm{H}_{11 \mathrm{~A}}$ : Regardless of the level at which an OL instructor teaches (undergraduate, graduate or both), OL instructors' perceptions differ between OL versus FTF education.

$\mathrm{H}_{10 \mathrm{~B}}$ : Regardless of the level at which a FTF instructor teaches (undergraduate, graduate or both), FTF instructor's perceptions are indifferent between OL versus FTF education.

$\mathrm{H}_{11 \mathrm{~B}}$ : Regardless of the level at which a FTF instructor teaches (undergraduate, graduate or both), FTF instructors' perceptions differ between OL versus FTF education. 


\section{Number of Years Taught at University \& Total.}

Theoretically, instructors with more teaching experience may perceive OL and FTF education differently. Therefore, we assume that their perspectives are not different and seek to uncover the significant differences. Specifically:

$\mathrm{H}_{20 \mathrm{~A}}$ : Regardless of the number of years than an OL instructor has taught, OL instructor's perceptions are indifferent between OL versus FTF education.

$\mathrm{H}_{21 \mathrm{~A}}$ : Regardless of the number of years than an OL instructor has taught, OL instructor's perceptions differ between OL versus FTF education.

$\mathrm{H}_{20 \mathrm{~A}}$ : Regardless of the number of years than a FTF instructor has taught, FTF instructor's perceptions are indifferent between OL versus FTF education.

$\mathrm{H}_{21 \mathrm{~B}}$ : Regardless of the number of years than a FTF instructor has taught, FTF instructor's perceptions differ between OL versus FTF education.

\section{Took OL course At University or Elsewhere.}

An instructor may have taken an online course themselves, which by virtue of participating as a student, may impact upon their perceptions of online and FTF education. With this in mind, we propose the following hypotheses:

$\mathrm{H}_{30 \mathrm{~A}}$ : Regardless of whether an OL instructor has taken an online course, OL instructor's perceptions are indifferent between OL versus FTF education.

$\mathrm{H}_{31 \mathrm{~A}}$ : Regardless of whether an OL instructor has taken an online course, OL instructor's perceptions differ between OL versus FTF education. 


\section{The BRC Academy Journal of Business Vol. 9, No. 1}

$\mathrm{H}_{30 \mathrm{~B}}$ : Regardless of whether a FTF instructor has taken an online course, FTF instructor's perceptions are indifferent between OL versus FTF education.

$\mathrm{H}_{31 \mathrm{~B}}$ : Regardless of whether a FTF instructor has taken an online course, FTF instructor's perceptions differ between OL versus FTF education.

\section{Self-reported Technology Level.}

By virtue of their own backgrounds, instructors bring their own confidence in their technological skill and comfort to a classroom. The instructor's technological skill may impact their perceptions of OL and FTF education. With this in mind, we propose the following hypotheses:

$\mathrm{H}_{40 \mathrm{~A}}$ : Regardless of the OL instructor's self-reported technological skill, OL instructor's perceptions are indifferent between OL versus FTF education.

$\mathrm{H}_{41 \mathrm{~A}}$ : Regardless of the OL instructor's self-reported technological skill, OL instructor's perceptions differ between OL versus FTF education.

$\mathrm{H}_{40 \mathrm{~B}}$ : Regardless of the FTF instructor's self-reported technological skill, FTF instructor's perceptions are indifferent between OL versus FTF education.

$\mathrm{H}_{41 \mathrm{~B}}$ : Regardless of the FTF instructor's self-reported technological skill, FTF instructor's perceptions differ between OL versus FTF education.

We conducted our study at a mid-sized, Jesuit, Catholic, private school with a focus on teaching. The research focus lies in uncovering instructor perceptions at a university that offers instruction in traditional arts and sciences, education and business and where FTF class sizes average 17 students. While online education is a growing educational method (Allen \& Seaman, 2013), not all faculty have been trained in or participated in 
online course development. Based upon the literature, the intent of this research is to explore instructors' perceptions of the online experience for those who have taught in and those who have never taught in the online environment based upon the instructors' experiences. Specific perceptions include: motivation, discipline, self-directed learning and independence, time and cost investment, preference, happiness and appropriateness for learning environment, online orientation, cultural differences, course organization, academic rigor, program quality, academic integrity, instructor-to-instructor involvement, student-to-instructor interaction, student-to-student interaction, communication mechanisms, and program technologies. Theoretically, instructors should perceive the environments equally and not favor either traditional or online education.

\section{PREVIEW COMPLETE}

This completes the limited preview of this paper. Please visit the link below to purchase.

\section{Citation Information}

Fish, Lynn A., and Coral R. Snograss. "Experience Demographic Factors and their Influence on Instructor Perspectives of Online versus Face-to-Face Education at a Jesuit Institution.” The BRC Academy Journal of Business 9, no. 1 (2019): 75-100. http://dx.doi.org/10.15239/ j.brcacadjb.2019.09.01.ja05 